\title{
Pentoxifylline inhibits intimal hyperplasia and vascular smooth muscle cell proliferation in a rabbit carotid artery anastomosis model
}

\author{
Ali Aycan Kavala ${ }^{1 \star}$, Koray Aykut ${ }^{2}$, Emrah Sisli ${ }^{3}$, Yusuf Kuserli $^{4}$, Bekir Ugur Ergur ${ }^{5}$, \\ Eyup Hazan ${ }^{2}$ and Gokhan Albayrak ${ }^{2}$
}

\footnotetext{
${ }^{1}$ Department of Cardiovascular Surgery, Bakırkoy Dr. Sadi Konuk Training and Research Hospital, Istanbul, Turkey.

${ }^{2}$ Medical Park Hospital, Department of Cardiovascular Surgery, Izmir University, Izmir, Turkey.

${ }^{3}$ Clinics of Cardiovascular Surgery, Antakya State Hospital, Hatay, Turkey.

${ }^{4}$ Clinics of Cardiovascular Surgery, Kahramanmaras State Hospital, Kahramanmaras, Turkey.

${ }^{5}$ Department of Histology and Embryology, Dokuz Eylul University, Izmir, Turkey.
}

Accepted 8 April, 2013

\begin{abstract}
This study aimed to evaluate the inhibitory effect of pentoxifylline, a phosphodiesterase inhibitor on intimal hyperplasia (IH) and vascular smooth muscle cell proliferation in an anastomosis model of rabbit carotid artery (CA). Right CAs of 18 male New Zealand white rabbits were anastomosed under general anesthesia. After the surgical procedure, 18 rabbits were separated into three study groups, 6 in each. Group 1 (control group) did not receive any treatment. Group 2 and 3 were treated with 100 $\mathrm{mg} / \mathrm{kg} /$ day subcutaneous pentoxifylline for 7 and 21 days, respectively. After 28 days, histopathological assessments and histomorphometric measurements were performed on the CA segments. In the histological sections, IH was less evident in the anastomosed vessel wall in pentoxifylline-treated groups than in Group 1. The mean luminal diameter (LD), luminal area (LA), intimal thickness (IT), and intima/media ratio (IMR) for Group 1 were $472.63 \pm 13.28 \mu \mathrm{m}, 301,973.33 \pm 12,951.27 \mu^{2}, 200,844.67 \pm$ $8,375.38 \mu \mathrm{m}$, and $0.52 \pm 0.01$, respectively. The LD and LA were significantly higher, and the IT and IMR were significantly lower for Group 2 and 3 compared with Group $1(p<0.05)$. However, there was no significant difference between Groups 2 and 3 for these variables $(p>0.05)$. Subcutaneous pentoxifylline treatment, even for duration of only seven days decreases IH in arterial anastomosis sites in a rabbit CA anastomosis model.
\end{abstract}

Key words: Pentoxifylline, vascular graft, anastomosis, carotid arteries.

\section{INTRODUCTION}

Reconstructive vascular surgery is a common intervention for the treatment of obstructive arterial disease that is less successful than expected due to the development of spontaneous thrombosis or restenosis after the surgery (Ducasse et al., 2003). While spontaneous thrombosis is responsible for the obstruction of the vessel in the early period, intimal hyperplasia $(\mathrm{IH})$ leads to restenosis after surgery in the long-term.

Intimal hyperplasia $(\mathrm{IH})$ is defined as the abnormal migration and proliferation of vascular smooth muscle cells with associated deposition of extracellular connective tissue matrix (Davies and Hagen, 1994; Subbotin, 2007). It develops in response to vessel wall injury, leading to luminal stenosis and occlusion (Davies and Hagen, 
1994; Bauters and Isner, 1997; Schwartz et al., 1992). Growth factors, hormonal factors, and mechanical factors play role in the process of IH (Bauters and Isner, 1997; Purcell et al., 1997). Prevention of $\mathrm{IH}$ after surgery is dependent on the pharmacologic suppression of subendothelial smooth muscle proliferation and synthesis of extracellular matrix (Sottiurai, 1990).

Pentoxifylline (PTX), a methylxanthine derivative, is a phosphodiesterase inhibitor with potent hemorheologic properties (Samlaska and Winfield 1994; Schönharting et al., 1988). It is used in the treatment of peripheral vascular disease, cerebrovascular disease, and a number of other conditions involving defective regional microcirculation (Ward and Clissold, 1987). It has antimitogenic effects and inhibits collagen synthesis; these effects are mediated predominantly through a cyclic adenosine monophosphate (CAMP)-dependent protein kinase (PKA) effector pathway (Chen et al., 1999).

Chen et al. (1999) showed that PTX inhibited proliferation and collagen synthesis in rat vascular smooth muscle cells under both basal and platelet-derived growth factor (PDGF) or transforming growth factor-beta (TGFbeta)-stimulated conditions. Hansen et al. (1999) found that PTX inhibited neointimal formation and induced constrictive vascular remodeling in a rat model of balloon injury by mechanisms involving decreased collagen type I production by vascular smooth muscle cells. In a recent study, it was shown that subcutaneous PTX treatment induced less proliferation within the vessel wall and increased lumen size after balloon angioplasty of the iliac artery of rabbits. It also has a positive effect on vascular remodeling (Busk et al., 2008).

On the basis of current evidence on the antimitogenic effects of PTX in animal models, we aimed to evaluate the effects of PTX on IH and vascular smooth muscle cell proliferation in an anastomosis model of the rabbit carotid artery (CA). We believe that the anastomosis model is superior to balloon angioplasty which has been used in previous studies, in that it is more similar to injuries that may occur during vascular surgery because it affects all three layers of the vessel wall.

\section{MATERIALS AND METHODS}

\section{Experimental design and animals}

This was a randomized, controlled experimental study. Eighteen male New Zealand white rabbits (2 to $3 \mathrm{~kg}$ ) were used. All animals were kept in an air-conditioned environment in natural daylight at a room temperature of $20 \pm 2^{\circ} \mathrm{C}$. They were fed ad libitum. This study conforms to the Guide for the Care and Use of Laboratory Animals published by the US National Institutes of Health (NIH Publication No. 85-23, revised 1996) and was approved by the Dokuz Eylul University Local Ethics Committee for Animal Studies.

\section{Surgical procedure}

Before the surgery, a cannulae was inserted into the marginal ear vein for intravenous access. Surgical anesthesia was induced with $50 \mathrm{mg} / \mathrm{kg}$ of intramuscular ketamine and $5 \mathrm{mg} / \mathrm{kg}$ of xylazine (Rompun; Bayer, Munih, Germany). For infection prophylaxis, 50 $\mathrm{mg} / \mathrm{kg}$ of intravenous cefazolin (Cefazol; Mustafa Nevzat, Istanbul, Turkey) was applied preoperatively. The right carotid artery (CA) was used for anastomosis and the left CA was left as control. The surgical area was prepared with $10 \%$ povidone iodine solution. A vertical incision was made on the right side of the neck and the right CA was explored. Following intravenous heparinization (100 IU/kg), the right CA was carefully dissected from the surrounding tissue. Bulldog-clamps were placed in the proximal and distal part of the $\mathrm{CA}$, the artery was transected and anastomosed in an end-to-end fashion end-to-end using $8 / 0$ polypropylene sutures. The clamps were then removed to re-establish blood flow (Figure 1). The anastomosis procedure was performed by the same investigator for all rabbits.

\section{Experimental groups}

After the surgical procedure, 18 rabbits were separated into three study groups, 6 in each. Group 1 (control group) did not receive any treatment. Group 2 and 3 were treated with $100 \mathrm{mg} / \mathrm{kg} /$ day subcutaneous PTX for 7 and 21 days, respectively. After 28 days, the right and left CAs of all animals were dissected free under general anesthesia and the arterial segments were sent to the Histopathology Laboratory for histological evaluation. Animals were euthanized with an intravenous overdose of pentobarbital sodium after 28 days. All of the rabbits lived for the entire study period without any neurological defects or wound infection.

\section{Histopathological assessments}

Specimens were fixed with $10 \%$ formaldehyde solution and embedded in paraffin. Serial cross-sections at $5 \mu \mathrm{m}$ were obtained by cutting the paraffin blocks at the level of anastomosis with rotary microtome (Leica RM, 2135, Leica instruments, Nussloch, Germany). Afterwards, the specimens were stained with hematoxylin-eosin and Masson's trichrome. Sections of anastomozed and the corresponding contrlateral sides were evaluated under light microscope (Olympus BH-2, Tokyo, Japan). Photomicrographs were taken with a high-resolution video camera (JVC TK-890E, Japan).

\section{Histomorphometric analysis}

Photomicrographs were evaluated with digital image analysis software (UTSCSA; Image tool version 3.0, University of Texas, San Antonio, Texas, US). The thickness and area of the tunica media and intima, as well as the diameter and area of the vessel lumen, were stereologically measured for each vessel. The luminal diameter (LD) was calculated as the mean value of the three diameters. The luminal, intimal and medial areas were measured manually by encircling the area of lumen, internal and external elastic lamina. Afterwards, intimal area is calculated as the difference of the area of internal elastic lamina and luminal area (LA). The medial area is the substraction of the area of external elastic lamina from internal elastic lamina. Additionally, photomicrographs were converted into $3 \mathrm{D}$ images using Reconstruct 1.0.9.9 software (Excel Company; Brescia, Italy).

\section{Statistical methods}

The Statistical Package for the Social Sciences for Windows 


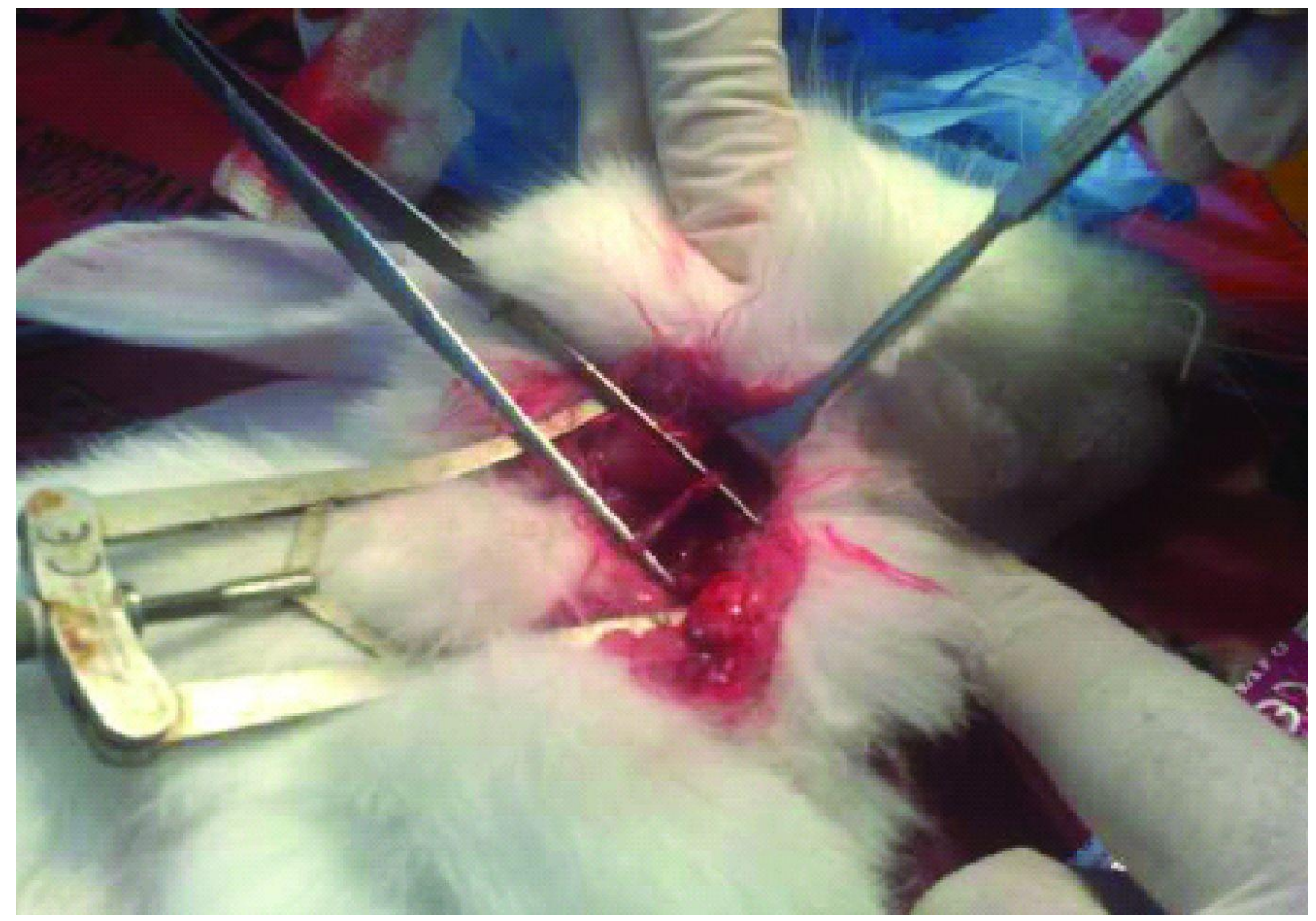

Figure 1. Exposure of the right carotid artery.

(version 11.0; Rel. 11.0.1. 2001, SPSS Inc., Chicago, IL, USA) was used for statistical analysis. Data were presented as mean \pm standard error of the mean (SEM). Analysis of variance (ANOVA) was used to evaluate differences between experimental groups. For post-hoc multiple comparisons, the Bonferroni test was used. Statistical significance level was defined as $p<0.05$.

\section{RESULTS}

\section{Histopathological evaluation}

In the sections of Group 1, the arterial lumen was almost entirely occluded, along with recanalizations in some sections. Other findings in these sections were $\mathrm{IH}$ due to smooth muscle cell proliferation, an increase in connective tissue, and intense fibrous tissue formation external to the tunica adventitia (Figure 2a). In contrast, the lumens of CAs of Group 2 were remarkably wider than the lumens of CAs of Group 1. In comparison with Group 1, the average intimal thickness (IT) was lesser and the tunica media was higher. However, recanalizations and adhesions, as well as areas of IH extending into the lumen were present in some sections (Figure 2b). In the sections of Group 3, the IT was less and the arterial lumen was wider than that of arteries from Groups 1 and 2 (Figure 2c).

In the histological sections of anastomosed right CAs, $\mathrm{IH}$ was less pronounced in the vessel walls of Group 2 and 3 than that of Group 1 (Figure 3). The structure of the intima and the lumen was normal in the sections of the contralateral left CAs in all three groups (Figures 2 and 3).

\section{Three dimension (3D) reconstruction of ımages}

In the 3D histological section images assembled using 3D Reconstruct for Windows 1.0.9.9, it was seen that IH was intense in Group 1, but lesser in Group 2 and 3. IT in Group 3 was lower than Group 2 (Figure 4). The vascular structures and lumen volume were normal in left CAs and were similar in 3D sections to those in all study groups (Figure 4).

\section{Histomorphometric measurements}

\section{Luminal diameter}

In Group 1, the LD was significantly lower in the right CA than the left $(472.63 \pm 13.28 \mu \mathrm{m}$ versus $808.29 \pm 11.27$ $\mu \mathrm{m}, \mathrm{p}<0.05)$. In Groups 2 and 3, however, the LD of the right CA was significantly higher than that of Group $1(p<$ 0.05 ). There was no significant difference between the LDs of Group 2 and 3 ( $p=0.865$ ) (Figure 5a). 

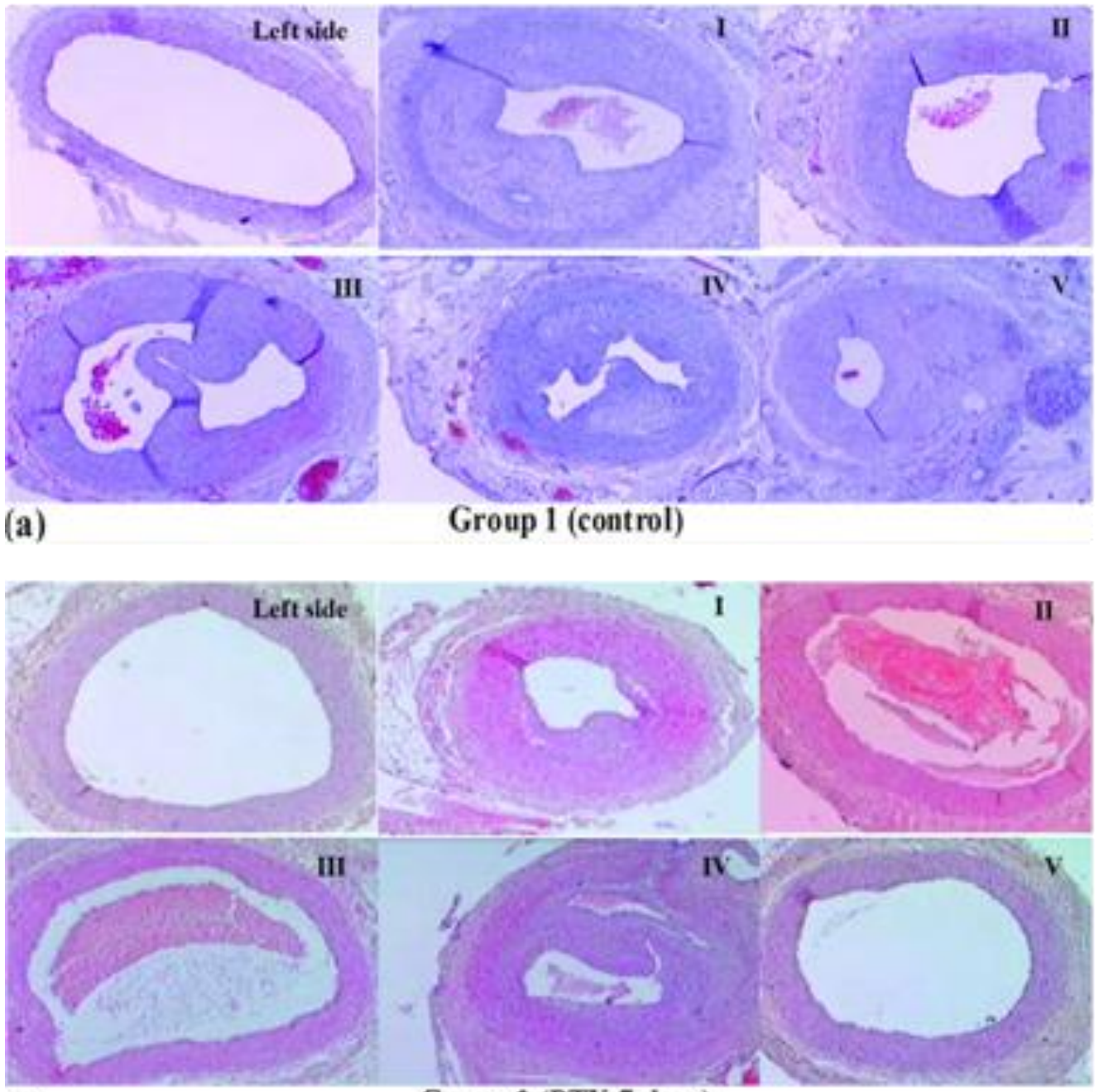

(b)

Group 2 (PTX 7 days)

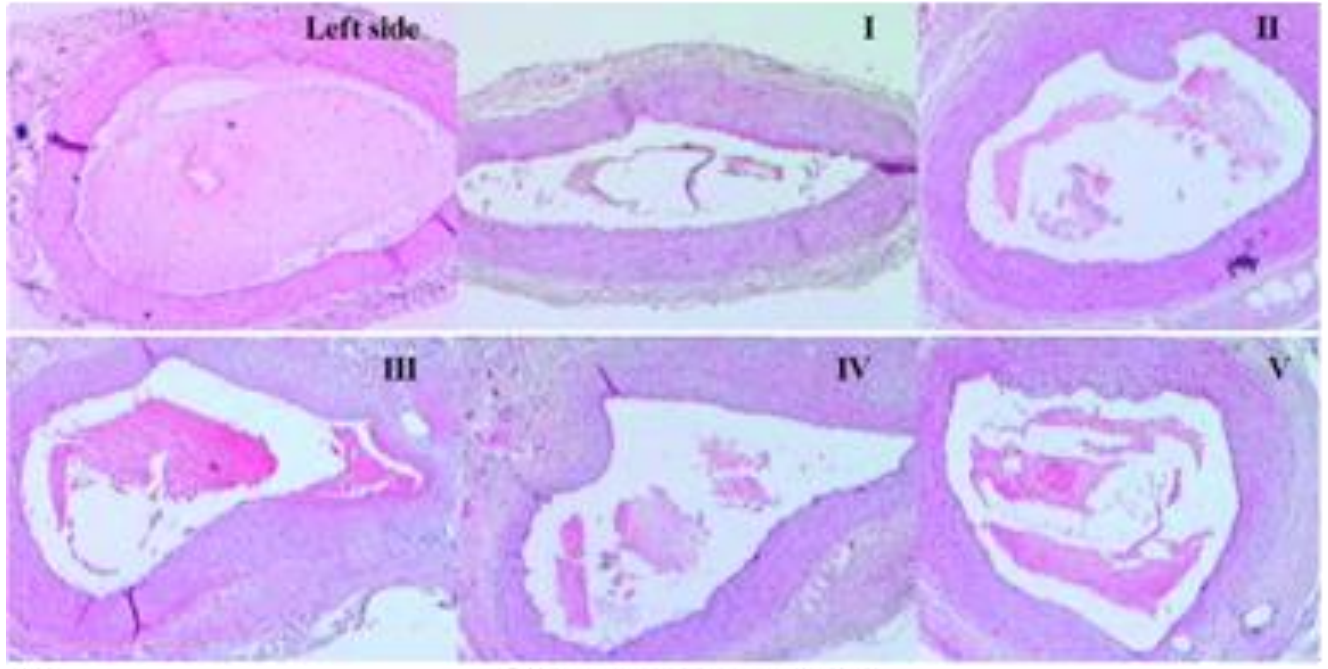

(c)

Group 3 (PTX 21 days)

Figure 2. Histopathological assessment of the study groups. *PTX: pentoxifylline. 

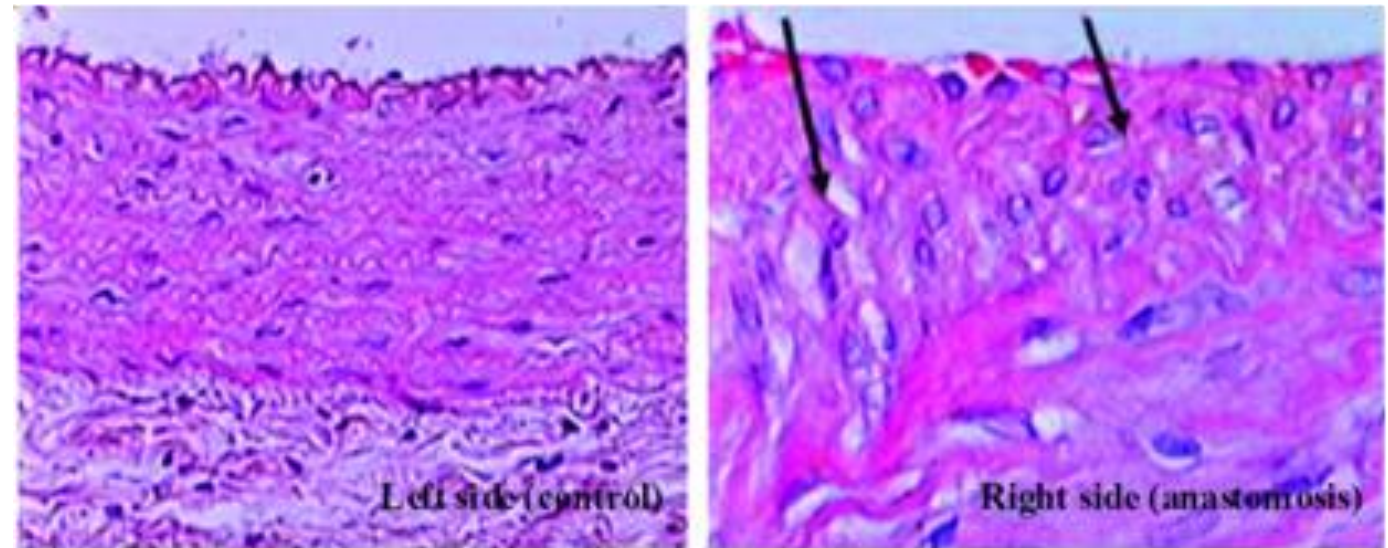

a)

Grouv 1 (control)
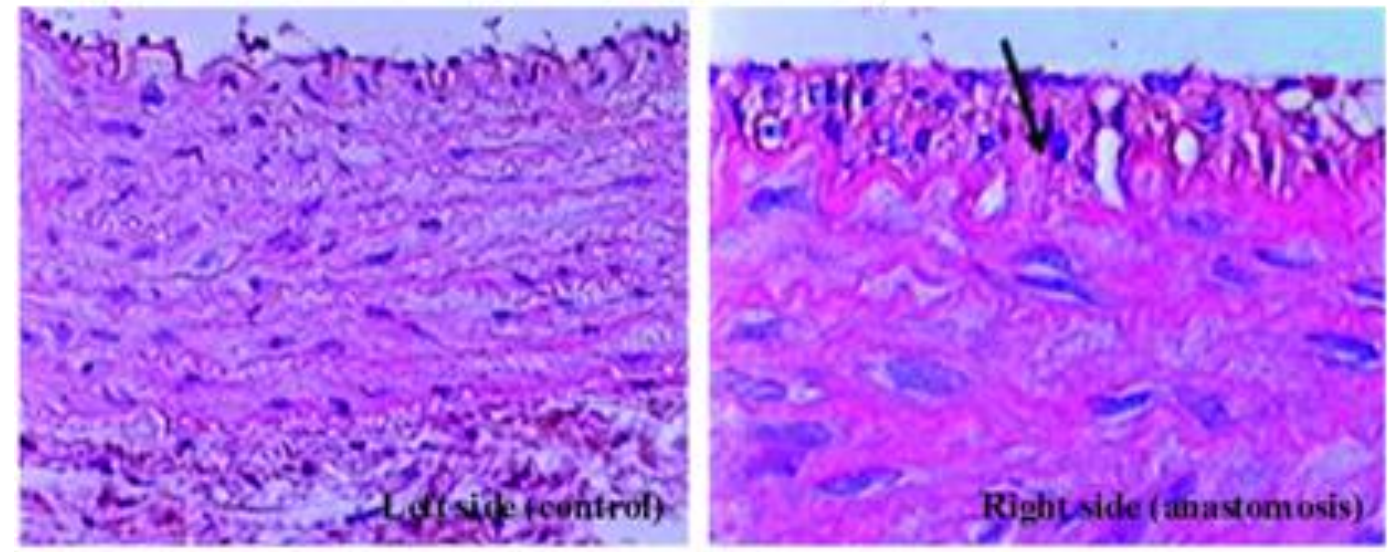

b)

Group 2 (PTX 7 days)
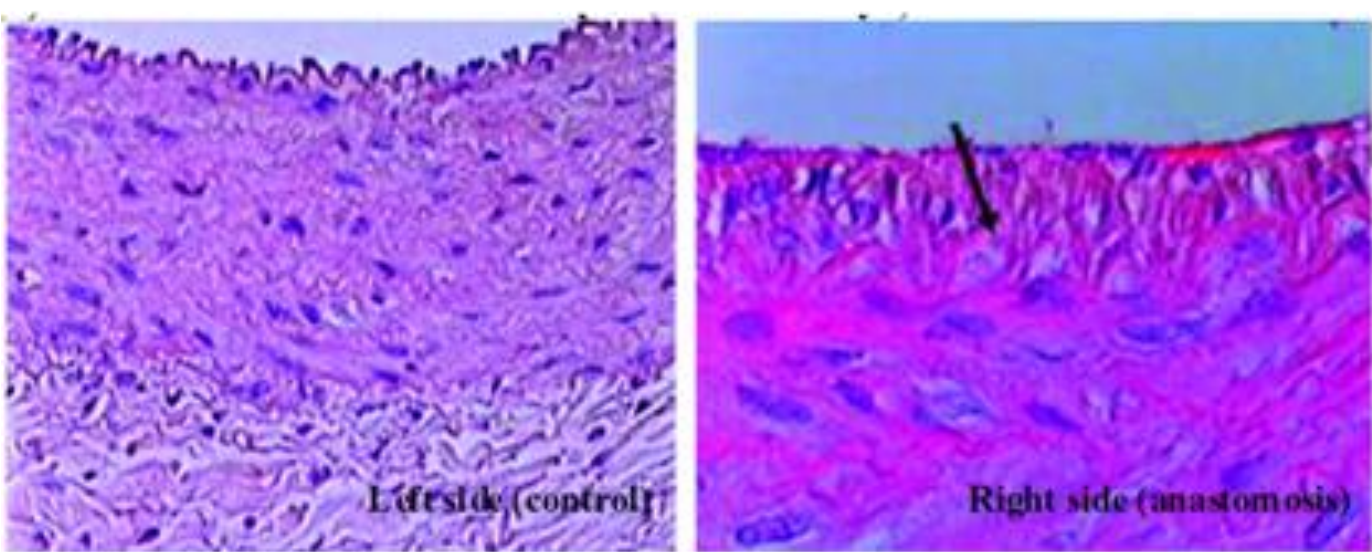

c)

\section{Group 3 (PTX 21 days)}

Figure 3. Comparison of left side (control) and right side (anastomosis) in histopathologic sections.

\section{Luminal area}

Measurements of serial cross-sections showed that the vascular LA of the right CA in Group 1 was lower than that of the contralateral side $\left(301,973.33 \pm 12,951.27{\mu m^{2}}^{2}\right.$ versus $\left.501,576.67 \pm 13,104.00 \mu \mathrm{m}^{2}\right)$, but this difference was not statistically significant $(p>0.05)$. In comparison with Group 1, the LA of right CA was significantly higher in Groups 2 and $3(p<0.005)$. Group 3 had a larger LA of anastomosed CAs than Group 2, but this difference was 
(a)
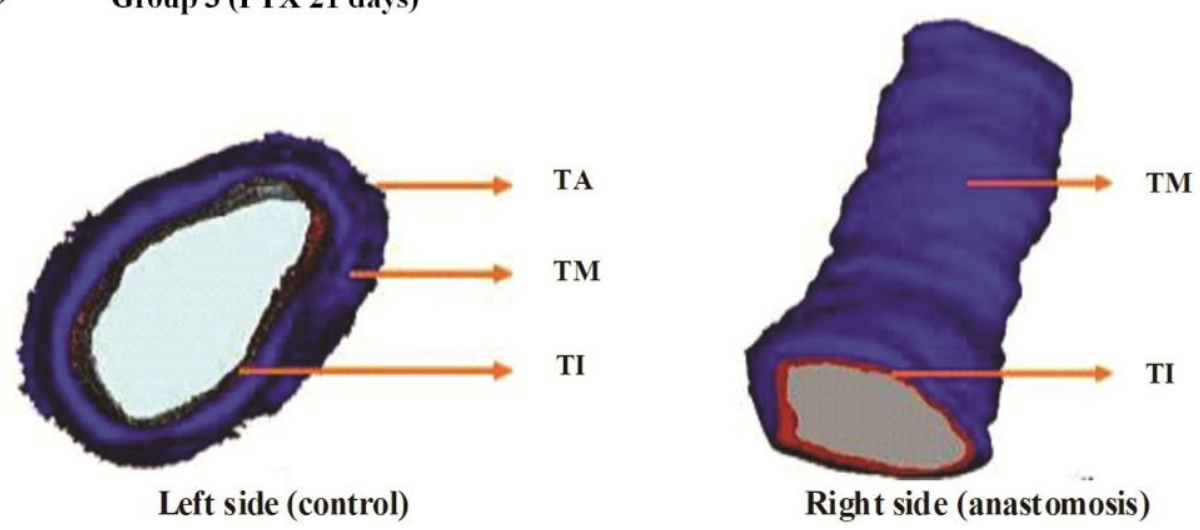

(b)

Group 1 (Control)

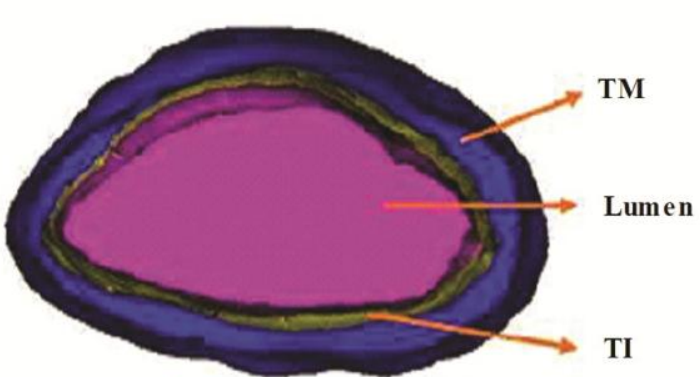

Left side (control)

(c) Group 2 (PTX 7 days)

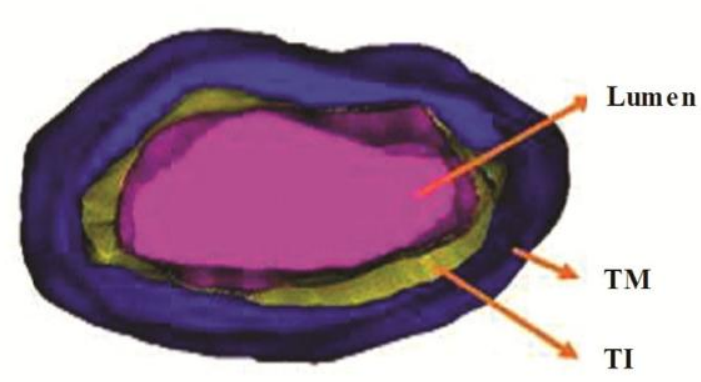

Left side (control)

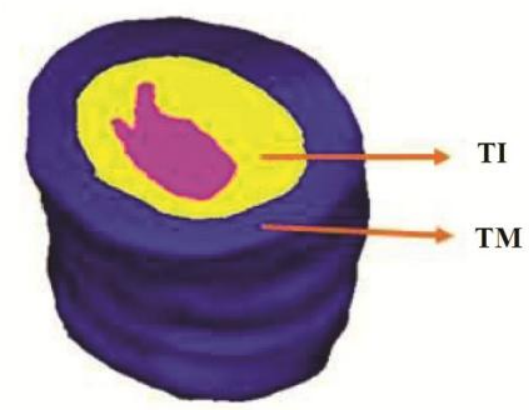

Right side (anastomosis)

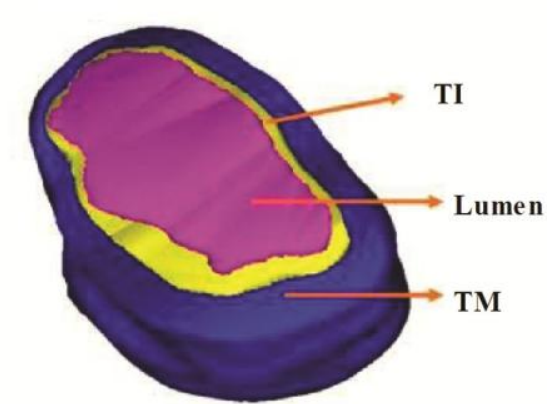

Right side (anastomosis)

Figure 4. 3D reconstruction of the images of the vascular structures.

*TA: Tunica adventitia, TM: Tunica media, TI: Tunica intima. PTX: Pentoxifylline.

not significant $(p=1.000)$ (Figure 5a).

\section{Intimal thickness}

The mean IT was significantly higher in right CA than left in Group $1(200,844.67 \pm 8,375.38 \mu \mathrm{m}$ versus $33,429.50$ $\pm 817.50 \mu \mathrm{m}, \mathrm{p}<0.05)$. The IT decreased significantly with PTX treatment $(p<0.001$ for both Group 2 versus
Group 1 and Group 3 versus Group 1). However, there was no significant difference between Groups 2 and 3 in terms of IT $(p=1.000)$ (Figure $5 b)$.

\section{Intima/media ratio}

The ratio of the intima to media (IMR) in serial crosssections was significantly higher in right than left for all 
(a)

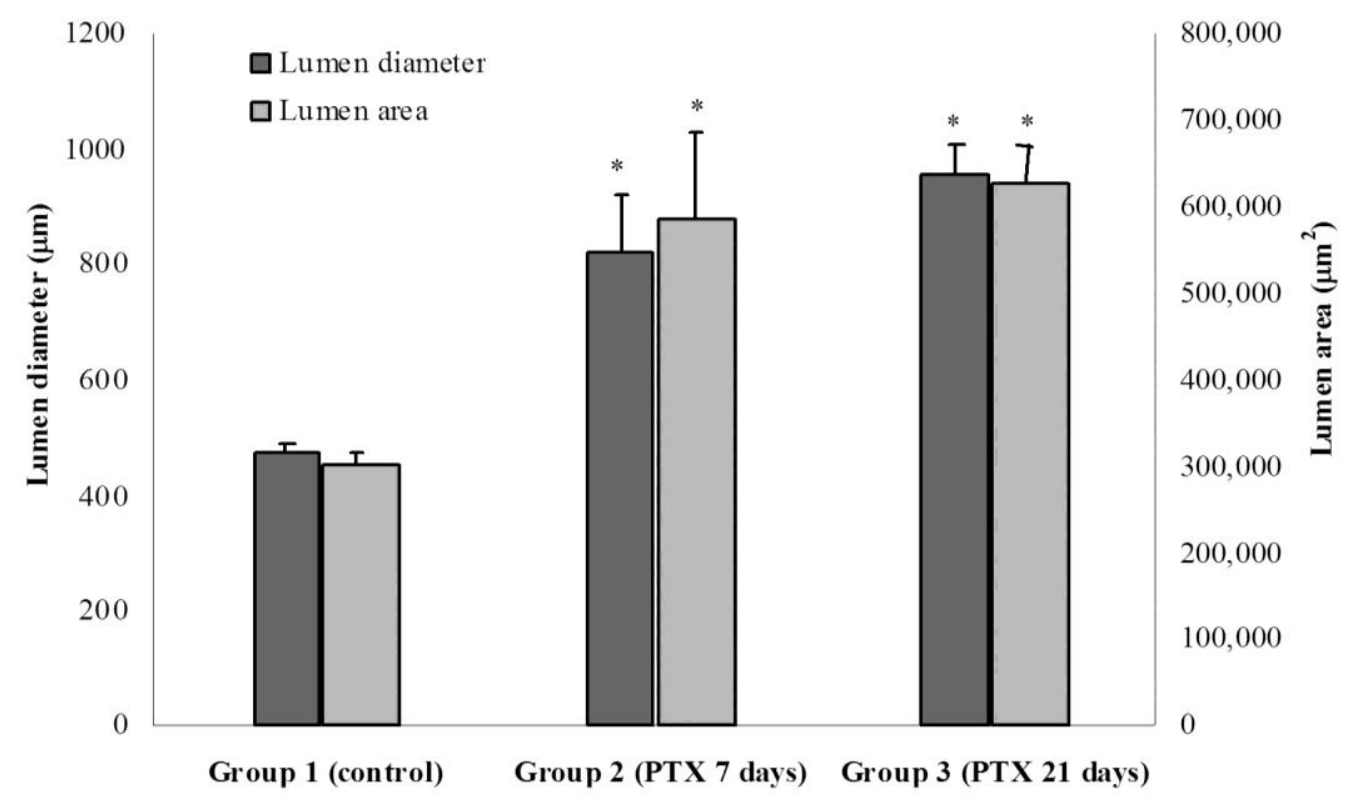

(b)

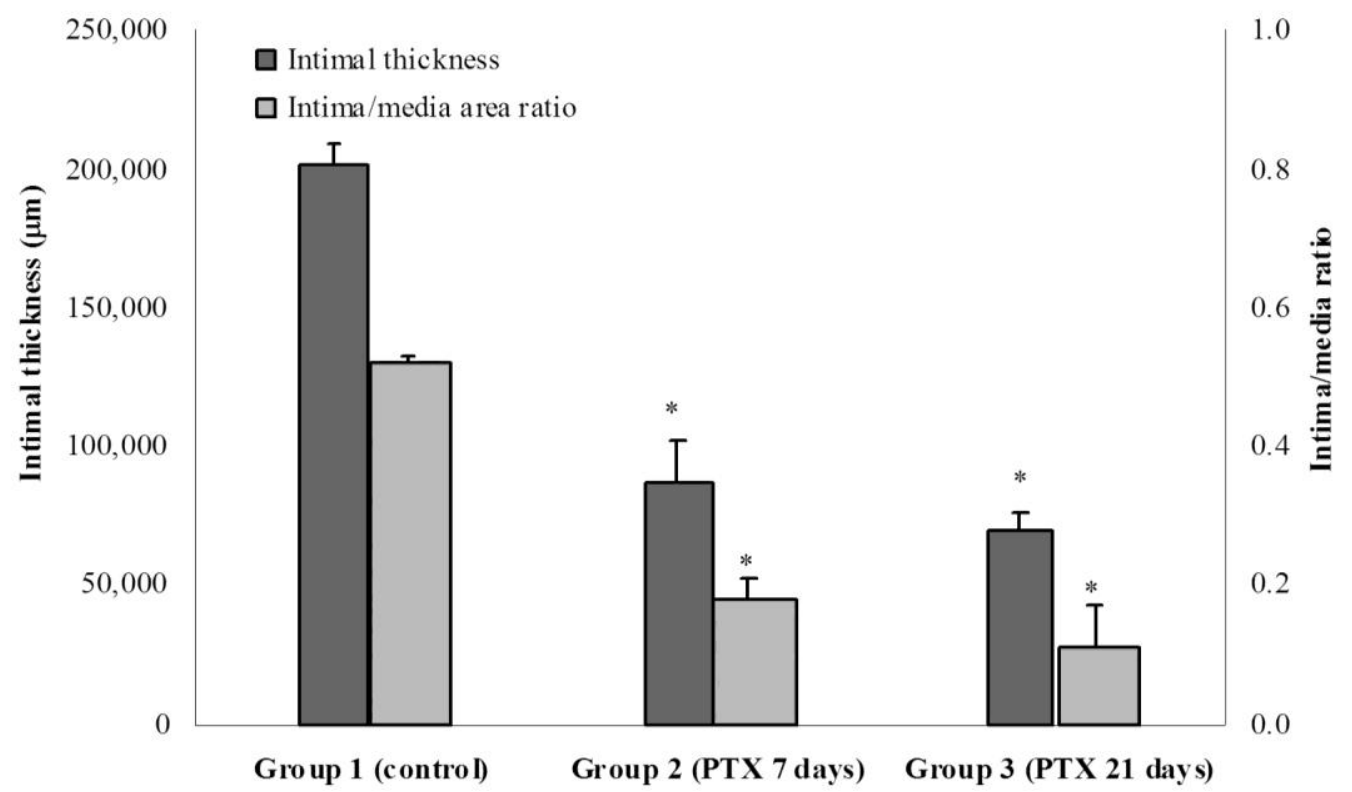

Figure 5. Measurements of luminal diameter-luminal area and intimal thickness-intimal/media area ratios in the study groups.

*PTX: pentoxifylline.

study groups $(p<0.05)$. The IMR of the anastomosed CA was $0.52 \pm 0.01,0.18 \pm 0.03,0.11 \pm 0.06$ for Groups 1,2 , and 3 , respectively. The IMR was significantly lower in Groups 2 and 3 compared with Group $1(p<0.05$ and $p<$ 
0.001 , respectively) (Figure $5 b$ ). Although the mean IMR in group 2 was higher than that of group 3, there was no significant difference $(p=1)$. The left CA was not significantly different between study groups in terms of LD, LA, IT, and IMR ( $p>0.05)$.

\section{Discussion}

In this study, we evaluated the effects of PTX on IH and vascular smooth muscle cell proliferation in injured arteries by using an anastomosis model of rabbit CA. We found that subcutaneous PTX treatment for 7 or 21 days after CA anastomosis significantly increased the LD and LA; and decreased the IT and IMR in comparison with the control group that received no treatment. Although PTX treatment for 21 days resulted in more favorable results than treatment for 7 days, the difference between the 7day and 21-day groups was not significant for any of the study variables. In spite of recent developments in vascular surgery, restenosis remains a primary postsurgical complication. Restenosis reduces the vascular lumen and ultimately induces thrombosis. $\mathrm{IH}$ and arterial remodeling have been identified as the underlying mechanisms of restenosis after vascular interventions (Bauters and Isner, 1997; Galt et al., 1993; Glagov, 1994). Therefore, $\mathrm{IH}$ is the major cause of failure after arterial reconstruction. The biology of $\mathrm{IH}$ is complex, and attempts at treatment have been disappointing (Subbotin, 2007; Zubilewicz et al., 2001). Although various agents have been studied for prevention of $\mathrm{IH}$ (O'Donohoe et al., 1991; Hamon et al., 1998; Takahashi et al., 1999; Takiguchi et al., 1995), restenosis continues to be a clinical problem after vascular surgery.

PTX increases the intracellular concentration of cAMP by inhibiting intracellular CAMP phosphodiesterase (Bienvenu et al., 1995; Mandell, 1995). Increased intracellular CAMP is thought to be responsible for most of the known effects of PTX, such as inhibition of vascular smooth muscle cell proliferation, reduction of blood viscosity, increased red blood cell deformability, decreased potential for platelet aggregation and thrombus formation, and inhibition of tumor necrosis factor (TNF)-alpha (Ward and Clissold, 1987; Bienvenu et al., 1995; Mandell, 1995; Strieter et al., 1988). PTX also suppresses inflammatory vascular damage and inhibits the effects of several cytokines (Mandell, 1995).

Previous studies on animal models using balloon angioplasty have shown that PTX reduces $\mathrm{IH}$. Hansen et al. (1999) examined the effects of PTX in SpragueDawley rats treated with intraperitoneal PTX (75 $\mathrm{mg} / \mathrm{kg} /$ day) or saline first dose being initiated 3 days before injury and continued until the 14th day after carotid balloon injury (total of 17 days). At 14th day of balloon injury, PTX significantly reduced the neointimal area, media area, IMR, and total vessel area. In vitro, PTX inhibits vascular smooth muscle cell production of collagen type I in a concentration-dependent manner without influencing vascular smooth muscle cell migration (Hansen et al., 1999).

Busk et al. (2008) recently investigated the effect of PTX on the vascular response to injury in a controlled study on rabbits that had undergone balloon angioplasty of the iliac artery, and treated with PTX (100 mg/kg/day) subcutaneously for 7 or 28 days after angioplasty or with placebo (saline) for 28 days after angioplasty. Although they did not compare the results of 7 and 28 day PTX treatment, they showed that angioplasty induced marked neoadventitial hyperplasia which was reduced by $20.5 \%$ $(p=0.01)$ in the PTX-treated group. PTX-treated rabbits had a $48.5 \%$ larger lumen area $(p=0.03)$ and a $28.1 \%$ larger area within the external elastic lamina $(p=0.04)$ at 28 days after injury. It has also been shown that PTX treatment leads to a more differentiated (less proliferation, more smoothelin-positive) intimal smooth muscle cell phenotype, reduced myofibroblast accumulation in the adventitia, and reduced collagen density in all three arterial layers (Busk et al., 2008).

In parallel to the findings of these previous studies, our findings showed that subcutaneous PTX treatment for 7 or 21 days after $C A$ anastomosis significantly increased the LD and LA; and decreased the IT and IMR in comparison with the control group that received no treatment. Histological sections and 3D reconstruction images also showed less IH in PTX-treated groups compared with the control.

Previous studies employed various vascular models in rabbits for evaluating the biological response to vascular injury, as well as a diversity of therapies designed to modify intimal hyperplasia (O'Donohoe et al., 1991; More et al., 1994). To explore a more clinically relevant type of injury, we performed CA anastomosis on the rabbits as the basis of our vascular injury model. More et al. (1994) reported that, using the rabbit model of balloon angioplasty to the iliac arteries, intimal thickening characterized by myointimal hyperplasia was observed at day 7 and reached a maximum at 1 month. Thus we evaluated the CAs 28 days after the anastomosis procedure, since $\mathrm{IH}$ is known to reach a maximum at 28 days after arterial injury.

In our study, in contrast to the previous studies, we used a rabbit CA anastomosis model which used a balloon angioplasty model. In the balloon angioplasty model, we think only that the tunica intima is damaged due to shear stress. In the anastomosis model, on the other hand, all three layers of the vessel wall - the tunica intima, media, and adventitia are injured. In this respect, the anastomosis model better resembles injuries received during vascular surgery. Furthermore, this model provides an assessment of the effects of PTX on the injured media and adventitia layers in addition to the tunica intima. 
The anastomosis model in our study induced $\mathrm{IH}$ in the CAs. In the histological sections from the anastomosed CAs of Group 1, occlusion of the arterial lumen was observed, along with recanalizations in some sections, $\mathrm{IH}$ due to smooth muscle cell proliferation, an increase in connective tissue, and intense fibrous tissue formation external to the tunica adventitia. In this study, we evaluated anastomosed right CAs in comparison with the contralateral left CAs (uninjured controls). We found that the intima and lumen structure, as well as the histomorphometric measurements, were within normal limits in the sections from the left CA in all three groups, without any difference. The major limitation of this study was the difficulty of extending the animal study results to human clinical applications. Therefore, further human studies on this subject are required. On another point of view, different dosages of PTX with variable durations of applications should be compared. The results of our study are expected to provide an important basis for these further studies.

\section{Conclusion}

We found that subcutaneous PTX treatment, even for a duration of 7 days, decreased $\mathrm{IH}$ in a rabbit CA anastomosis model. Thus, although PTX treatment for 21 days induced more inhibition of $\mathrm{IH}$, longer periods of treatment did not produce statistically significant differences in clinical outcomes.

\section{REFERENCES}

Ducasse $E$, Cosset JM, Eschwège $F$, Chevalier J, De Ravignan D, Puppinck P, Lartigau E (2003). Hyperplasia of the arterial intima due to smooth muscle cell proliferation. Current data, experimental treatments and perspectives. J. Mal. Vasc. 28:130-44.

Davies MG, Hagen PO (1994). Pathobiology of intimal hyperplasia. Br. J. Surg. 81:1254-69.

Subbotin VM (2007). Analysis of arterial intimal hyperplasia: review and hypothesis. Theor. Biol. Med. Model. 4:41.

Bauters C, Isner JM (1997). The biology of restenosis. Prog. Cardiovasc. Dis. 40:107-116.

Schwartz LB, O'Donohoe MK, Purut CM, Mikat EM, McCann RL, Hagen PO (1992). Myointimal thickening in experimental vein grafts is dependent on wall tension. J. Vasc. Surg. 15:176-86.

Purcell C, Tennant M, McGeachie J (1997). Neo-intimal hyperplasia in vascular grafts and its implications for autologous arterial grafting. Ann. R. Coll. Surg. Engl. 79:164-168.

Sottiurai VS (1990). Biogenesis and etiology of distal anastomotic intimal hyperplasia. Int. Angiol. 9:59-69.
Samlaska CP, Winfield EA (1994). Pentoxifylline. J. Am. Acad. Dermatol. 30:603-21.

Schönharting M, Musikić P, Müller R (1988). The haemorheological and antithrombotic potential of pentoxifylline: a review. Pharmatherapeutica 5:159-69.

Ward A, Clissold SP. Pentoxifylline (1987). A review of its pharmacodynamic and pharmacokinetic properties, and its therapeutic efficacy. Drugs 34:50-97.

Chen YM, Wu KD, Tsai TJ, Hsieh BS (1999). Pentoxifylline inhibits PDGF-induced proliferation of and TGF-beta-stimulated collagen synthesis by vascular smooth muscle cells. J. Mol. Cell. Cardiol. 31:773-783.

Hansen PR, Holm AM, Qi JH, Ledet T, Rasmussen LM, Andersen CB (1999). Pentoxifylline inhibits neointimal formation and stimulates constrictive vascular remodeling after arterial injury. J. Cardiovasc. Pharmacol. 34:683-689.

Busk M, Mertz H, Espersen GT (2008). Effects of pentoxifylline on the vascular response to injury after angioplasty in rabbit iliac arteries. Basic. Res. Cardiol.103:257-264.

Galt SW, Zwolak RM, Wagner RJ, Gilbertson JJ (1993). Differential response of arteries and vein grafts to blood flow reduction. J. Vasc. Surg. 17:563-570.

Glagov S (1994). Intimal hyperplasia, vascular modeling, and the restenosis problem. Circulation 89:2888-91.

Zubilewicz T, Wronski J, Bourriez A, Terlecki P, Guinault AM, Muscatelli-Groux B, Méllière D, Becquemin JP, Allaire E (2001). Injury in vascular surgery--the intimal hyperplastic response. Med. Sci. Monit. 7:316-324.

O'Donohoe MK, Schwartz LB, Radic ZI (1991). Chronic ACE inhibition reduces intimal hyperplasia in experimental vein grafts. Ann. Surg. 214:727-732.

Hamon M, Lécluse E, Monassier JP,Grollier G, Potier C (1998). Pharmacological approaches to the prevention of restenosis after coronary angioplasty. Drugs Aging 13:291-301.

Takahashi A, Taniguchi T, Ishikawa Y, Yokoyama B (1999). Tranilast inhibits vascular smooth muscle cell growth and intimal hyperplasia by induction of p21(waf1/cip1/sdi1). Circ. Res. 84:543-550.

Takiguchi Y, Nagano M, Ikeda Y, Nakashima M (1995). Early administration of YT-146, an adenosine A2 receptor agonist, inhibits neointimal thickening after rat femoral artery endothelium injury. Eur. J. Pharmacol. 281:205-207.

Bienvenu J, Doche C, Gutowski MC (1995). Production of proinflammatory cytokines and cytokines involved in the $\mathrm{TH} 1 / \mathrm{TH} 2$ balance is modulated by pentoxifylline. J. Cardiovasc. Pharmacol. 25(Suppl 2):S80-84

Mandell GL (1995). Cytokines, phagocytes, and pentoxifylline. J. Cardiovasc. Pharmacol. 25(Suppl 2):S20-22.

Strieter RM, Remick DG, Ward PA, Spengler RN, Lynch JP, Larrick J (1988). Cellular and molecular regulation of tumor necrosis factoralpha production by pentoxifylline. Biochem. Biophys. Res. Commun. 155:1230-1236.

More RS, Rutty G, Underwood MJ, Brack MJ, Gerschlick AH (1994). A time sequence of vessel wall changes in an experimental model of angioplasty. J. Pathol. 172:287-292. 